\title{
Electronic Mobile Devices, Transformative Pedagogy and Learning: Higher Education and Changing Times in Kenya
}

\author{
Anne A. Aseey \\ Senior Lecturer, Department of Research, \\ Evaluation and Lifelong Courses, \\ ODeL Campus, University of Nairobi, \\ P. O. Box 30197-00100, Nairobi, Kenya
}

\section{Agnes Anyango Andollo}

\author{
PhD Candidate, \\ Faculty of Psychology and Educational Science, \\ Department of Educational Science, \\ University of Porto, Portugal
}

Doi: 10.2478/jesr-2019-0022

\begin{abstract}
The Fourth Industrial requires new concepts and skills to be acquired by learners at various levels. This has led to a new breed of learners joining our education institutions at various levels with prerequisite knowledge on technology which can be harnessed for learning and teaching purposes. This scenario has generated a lot of interest and more research on how first the process of knowledge acquisition is changing. There is excited attention among researchers, educators, education commentators and stakeholders on this aspect of learning. The new generations of techno savvy leaners joining institutions are a challenge to the old pedagogy of teaching. These young generations are creating a digital gap between the old ways of teaching and learning to new approaches in education. The nature of the generation change needs to bring some reforms in education especially in higher education in Kenya where electronic mobile devices penetration has escalated for the last ten years. This research paper, highlights issues around use of electronic mobile devices for knowledge acquisition purposes which if well utilized can aid the education systems in most African Countries in terms of access, affordability, ease of use and leaners wide interaction and independent study. The old pedagogy of the teacher being the absolute source of information is being transformed by the use of an array of emerging devices like Smartphone, ipads, laptops and others which are readily available to the leaner's. The study was carried out among undergraduate and postgraduate students at the University of Nairobi, Kenya between 2016 to 2018. The researchers found out that, electronic mobile devices are with the students for ease of use. The study also found out that, some of leaners in higher institutions of learning are not well informed on how to utilize the mobile devices for learning purposes hence most of the time they are used for other purposes not related to learning. In general, most countries in Africa have tried to invest on internet connectivity, ICT Infrastructure, capacity building among others structure which can also be leveraged for Education needs.
\end{abstract}

Keywords: Digital natives, higher education, mobile devices, learning, Technology

\section{Introduction}

Education is basically considered as the foundation for economic growth and prosperity hence each and every country must invest in the education of its citizens. Globally, Education has gone through 
several changes with informed leaner's and educators on both sides. In Africa, the education system has improved from rote learning and basic skills acquisition to improved education systems capable of producing fairly globally competitive individuals. According to Incheon Declaration for Education 2030, different strategies and frameworks were set to improve the quality of education within the 160 countries who signed the declaration. One of the areas of commitment was on strengthening science, technology and innovation. They also stated that, Information and communication technologies (ICTs) must be harnessed to strengthen education systems, knowledge dissemination, information access, quality and effective learning and more effective service provision (Education 2030: Incheon Declaration 2015).

Education scholars have noted that, students at all levels live in a digital world which was hitherto unknown to the older generation hence the need for more research on technology, education and its impact. Haiti for instance had various economic, social and political challenges, but since 2010 a collaboration between Massachusetts Institute of Technology(MIT) from 2010, with various institutions in Haiti like FOKAL, Université Caraïbe, Faculté des Sciences and École Normale Supérieure of the Université d'État d'Haïti, École Supérieure d'Infotronique d'Haïti, Université Quisqueya, NATCOM among others focused on helping education institutions (Roxana,2013). This collaboration concept could also be replicated in other developing countries so that they seek assistance from those who have integrated ICT well in the education process. The Haitian initiative registered nearly 100 faculty participants and was able to reach more within the following years. On the same strength Bayne and Ross (2004) indicated that young people have grown up with computers and the internet and are naturally proficient with new digital technologies and spaces, while older people will always be a step behind and apart in their dealings with the digital issues.

In developed countries like the United States, Britain and others, the education systems are propelled through use of technology at all levels of the learning systems. This could be a big challenge to some developing countries in Africa where technology and its use in education is still a mirage. Though new methods of teaching using various devices are talking shape in many countries, there is need for more research in this area. UNESCO (2015) highlighted on the importance of education as key to human priority and that education dependence on human interaction between leaner and their teachers is crucial in any education endevours.

According to Bennet (2008), the immersion in technology-rich culture is said to impact on skills and knowledge acquisition and to generate interests of digital natives in a manner that is applicable to education needs and wants. It is asserted, for example, that digital natives learn differently compared with past generations of schooling systems. The digital natives are held to be active experiential learners and $Y$ possess sophisticated knowledge of and skills with available information devices (Bennet, 2008). Africa, in line with the global trends of developed countries, has also made some notably progress in relation to ICT in its major sectors of development like health, education and others. Adesida (2008) supported the sentiments as follows;

\section{'Africa must resolve to build a new society-an information and knowledge driven society based on the ethos of sustainability and equity between individuals, generations, communities and nations. We must endevour to create a people centred Africa where science and technology are tools for the betterment of actualization, and an opportunity to satisfy their material and spiritual needs' (p.240)}

Kenya is guided by different frameworks and policies which shape its education process. Key among the documents are; the Kenya constitution 2010 which supports the right to education for every citizen(Constitution of Kenya 2010), Kenya Vision 2030, the blueprint for national development takes into cognizance the role of science, technology and innovation(STI) and its benefits like creating an economic institutional regime that provides incentives for efficient use of existing knowledge, an educated and skilled workforce that can create ,share and utilize knowledge well and an effective innovation system among other variables. The vision 2030 is in tandem with international frameworks in ensuring that technological devices are used at all levels and education being the foundation must think more of integrating more technology into its curriculum at different levels (Kenya Vision 2030, 2007). 


\section{Electronic Mobile Devices and Learning}

UNESCO (2009) report indicated that, mobile technologies provide an excellent medium for extending educational opportunities to learners who may not have access to high-quality schooling. Sargeant et al. (2006) in their review of literature related to physician learning and interaction in face to face settings found that interpersonal interaction is one characteristic of effective interventions. The Kenyan Universities are achieving transformation in education by moving away from the old traditional modes of delivery which are classroom based to technological based learning and teaching which generates a multiplier effect on student numbers accessing university education (UNESCO, 2001). With a population projection of about 50 million in 2019, Kenya is among the countries in Africa which has made significant positive impacts in its education system in terms of ICT integration like offering computer as subject in its high school system, giving free tablets to government primary schools, having a nationwide ICT policy and other initiatives to enhance the use of ICT devices in education and other services within and outside the Country. This is in line with its Vision 2030 which recognizes that education and training of all its citizens is fundamental to the success of its vision as a country. Higher education in Kenya is keen in investing on the use ICT in education for better services. Aseey et al. (2009) noted that, the most highly rated administrative tasks in Universities included use of mobile phones at various university offices to communicate to students, rated at $90.2 \%$, use of online application forms for students rated at $87.6 \%$. The same findings were replicated in Gakuu (2005) which reckoned that lecturers are ready to adopt and adapt technology in the teaching and learning process. This is an indication that electronic mobile devices, could be suitable for learning purpose as leaner's use them anywhere, anytime and for most of their daily activities.

Republic of Kenya Report (1999), noted that there is massive expansion of technology and the need to keep abreast of it was recognized.The report recommended expansion of scientific and technological education at all levels for the production of adequate human resources to meet the demands of newly industrialized countries. In Africa, the use of technology in education has improved just like in the other sectors though many of the ICT programmes in most countries are still at infancy due to challenges like electricity, security, technical capacity among others. Countries which have made good trend in using ICT in education in Africa are South Africa, Egypt, Morroco Ghana, Kenya and Nigeria .In Kenya, there has been a rapid use of mobile devices among students which can be attributed to the high proliferation of electronic mobile devices which can be used for both social and academic purposes. Terry and Kennedy (2010) indicated in their study of biomedical students on-campus use of the internet that, 'Digital Native' students of the Net Generation' are technologically proficient and have a natural affinity with technologies. This is in line with what other countries like Kenya are experiencing with the 'Net Generation'

Other study findings like Heidi and George (2014) on teacher preparation programmes and technology integration found that, overall, the majority of the students respondents in the degree programs rated their ability to integrate technology into instruction as "Good." This reveals that, regardless of the type of education programme and its associated curriculum design, students perceived their preparation in educational technology as adequate. However, students completing their technology coursework scored more highly on questions about integrating technology into the classroom than did students new to their program of study. Therefore, in any given instance, the way electronic mobile devices are elected and integrated in the education systems can impact in different ways in which education is offered at various levels in different disciplines and geographical spaces.

Studies conducted in various countries still show that teacher is still in-charge of the learning situation in most educational settings. A report by Barber et al. (n.i) indicated that, each university needs to be clear which niches or market segments it wants to serve and how. In Kenya, the first Chancellors Convention in 2017 discussed the need to identify framework and actions for strengthening universities as bastions of national socio-economic development, unity in midst of diversity, cohesion, peace and security and also foster ideas, identify trends, note challenges and project future scenarios for enabling universities to drive the post-2015 sustainable development goals." 
The mobile learning community has also demonstrated that mobile technologies can enrich, enhance, and challenge existing ideas of education, usually in ways that take it outside and away from the classroom, the lecture, the teacher, and the curriculum, specifically by developing the ideas of informal, collaborative, contingent, situated, contextual, and personalized learning (Traxler, 2011).According to Mathew et.al.(2018) in their study, they noted that the emergence and application of mobile technologies as having a paradigmatic shift in approaches to learning, a shift which is highly variable across different settings and contexts. This could be the situation in most institutions as they try to use more mobile devices in the teaching and learning process. The study further noted that, the introduction of mobile technologies in learning was also 'tethered' like eLearning because of limited wireless phone connectivity (initially $2 G$ and then $3 G$ ) and unreliable Wi-Fi connectivity. Unlike the e-Learning paradigm, which was browser focused, the m-learning paradigm relies upon agile, mobile devices which belong to the individual. It is in this context that mobile learning paradigm is considered as representing a shift away from corporate technologies, owned and in most situations controlled by the institution, to more personal and pervasive devices that are inherently individual and more customized.

Various researchers agree that the use of ICT in education in general, and the Web, has consequences for the organization of education and how the teacher and the student relate. And with the mobile devices, they agree that their important features like portability, mobility and versatility remain the same. So \& Kint( 2008) noted that, these functions make learning ubiquitous in and out of classrooms, provide potential opportunities for collaborative learning and enrich the learning experiences with the support of technologies.

\section{Research Methodology}

We used survey design for this study. Research instruments used were questionnaires having both closed and open ended questions to get an insight into the problem under investigation. The purpose of this study was to basically assess the use of electronic mobile devices by University students in the teaching and learning processes as a transformative pedagogy with reference to University. The study carried out in the period 2016-early 2018 realized a questionnaire return rate of $99.8 \%$. The target population was 145 respondents and composed of 51 postgraduate doing master of arts in project planning and management and Master of science-Physics. The other respondents were 94 undergraduates' students from the following disciplines; education, computer science and human resource management. The research objective was to investigate the use of electronic mobile devices available in the hands of the students in relation to learning. Questionnaires were administered to the students during semester sessions so as to focus on the use of the devices for academic purposes.

\section{Study Findings}

The study found out that there was notably engagement with electronic mobile devices among the targeted students in this study. The common electronic mobile devices carried frequently by the students were; ipads, Laptops, mobile phones, iPhones and tablets. Almost 95\% of the respondents agreed that they carry the electronic devices to campus for various purposes and education was noted as one of the major reasons why they carried them to campus.

The devices were carried to class and were used both for social and academic purposes.98\% of the respondents indicated they go with the mobile phones to class while another $68 \%$ indicated that they carry other mobile devices like ipads,laptops among other electronic devices to class but use only when the lecturers are not in apart from the computer science students who can use them alongside their study time.

The respondents indicated that they use the devices when they don't have lecturers in class. This is an indication that the devices could be distortive to the teaching and learning process which $s$ considered to be face to face learning. The computer science students and Master of Science physics students indicated that that they use the laptops, smart phones and desktop computers when they have practical classes in the computer laboratories in the campus. The respondents also 
indicated that lecturers do not encourage use of electronic mobile devices in the lecturer hall due to such factors as disruption of the learning process, over concentration on the phone or on the internet and lack of interaction and direct communication between the lecturer and the students.

The respondents also agreed that technology gives them independence of study when the lecturers are not in or when they have free time they spend most of their time at the connected computer laboratories in the various university campuses or in any place where they can access internet for their use.

One of the master's students had this to say;

II use my smartphone most of the time to get updates in my field of study and to catch up with my classmates and friends on social media but for my lecturers, we use email'

While on computer science undergraduate student said that;

'It cannot just work for their course without a laptop. It's like everybody should have the device to survive in the course'

Technology also gives learners an opportunity for interacting with one another on projects and shred or group work in school. The students indicated that they work in groups then each individual proceeds to share her assigned task online which was easy for them because it saves time and even travelling expenses.

Receiving fast feedback was one of the factors that encouraged the students to use technology more as they get feedbacks from their colleges and even lecturers immediately when there is need. This is mostly possible with the use of the internet which the respondents indicated was available for use in the university.

The concept of personalized or individualized study was one other key findings of this study. $96 \%$ of the respondents agreed that, with electronic mobile devices like smartphone, Ipads, tablets and others, they are able to learn where never and wherever they are and also learn anything they want to learn or enhance on from sites like Youtube which was quite popular among students because of the videos and animations

Technology also helps leaner's gain personalized learning experiences that aligns to their learning styles and also gives them experiences that will prepare them for further education and the workplace as well as prepare them for their future careers and be responsible citizens..

For assessment purposes, technology can play an important role as it has lots of personal assessment and feedback which are immediate unlike the written assessment which the respondents indicated that were carried out mostly by the lectures. The computer science respondents and the master of physics indicated that they do a lot of online evaluation while studying online

Adapting to new technology takes time and also needs finances which are a challenge to most of the education sectors in developing countries. This study found out that $45 \%$ of the respondent has a challenge to acquiring electronic devices like smart phone and laptops which were more commonly used by the respondents in this study for academic purposes. And also, if they acquire them, the rate at which they get lost without the campus was also a worrying trend.

In reference to internet use, the study found out that the entire targeted student indicated that they access the internet daily with $85 \%$ accessing the internet on their electronic mobile devices and others at the university computer laboratories and at the Cyber Cafes mostly located outside the campus. The students mostly used the internet for browsing, accessing academic learning materials, for news purposes, sharing information, communication between their lecturers and fellow students, access software notes and research and social networking. The respondents in this study agreed that they carry mobile devices for learning purposes and administrative purposes with $25 \%$ agreeing that they call their tutors on academic related issues on their mobile phones though the calls are usually done by a class representative. They also make inquiries from the university administration using mobile phones but majority manage administrative issues through use of email services and SMS services.

In the study, mobile phone was the highest used device among the students as all the 
students targeted indicated that they have mobile phones which they carry class and other social places depending on the need. This can be attributed to the fact that, Kenya is one of the countries in Africa with the highest proliferation of mobile phones. According to (Nairobi, Kenya, The Quarterly Sector Statistics Report October ,2014) indicated that Kenya's mobile phone subscriptions grew by 5.6 percent over the last one year to stand at 32.2 million at the end of the 2013/2014 financial year fourth quarter, translating into a mobile penetration level of 79.2 percent. The number of new subscriptions registered during the period was 416,390 . Since then, there has been an upward trend on penetration of mobile phones in the country

The findings indicated that in $65 \%$ of the respondents had Smartphone's followed by ordinary mobile phones. The Smartphone seemed to be appealing to the students because of the various functions they can perform at a given time. For example, it has a touch screen interface which the respondent agreed was easy to operate, Internet access and other applications like camera, Bluetooth, games and others which the respondents agreed they use for various purposes

The use of lap top for academic purposes was also realized at $90 \%$ among the respondents with majority being the postgraduates and the science based undergraduate students. This could be as a result of different learning styles and learning activities among the undergraduate and postgraduate students in both the sciences and the arts courses

Another feature of electronic mobile devices and learning which the respondents indicated they use frequently is email. More than half of the respondents agreed they have email accounts which they use to communicate with their lecturers, fellow students, friends and family members. It was also noted that email was an official way in which the University communicates with the students and other staff since all the students and the staff have an official University email account.

Other common mobile electronic devices used by the respondents in this study were ipads, tablets and desktop computers.

\section{Discussions}

On personalized and individual learning, the study found out the electronic devices gives them opportunities to earn owns their own. This is supported by a study by Prensiky(2001) that indicated that, in math, for instance, the debate must no longer be about whether to use calculators and computers , since they are part of the Digital Natives" world but rather how to use them to instill the things that are useful to have internalized, from key skills and concepts to the adopting and adapting mobile learning.

The use of electronic mobile device in classroom by the respondents while in college was supported by a study conducted by Terry and Kennedy(2010) that, 'Digital Native' students of the Net Generation' are technologically proficient and have a natural affinity with technologies. This is in line with what other countries like Kenya are experiencing with the 'Net Generation'.

The Internet and mobile computing or mobile learning can provide access to education even in areas where there are not enough teachers. In the study, mobile phone was the highest used device among the students as all the students targeted indicated that they have mobile phones which they carry class and other social places depending on the need. This can be attributed to the fact that, Kenya is one of the countries in Africa with the highest proliferation of mobile phones. A report on mobile phone penetration in Nairobi, Kenya, by The Quarterly Sector Statistics Report October, 2014 indicated that Kenya's mobile phone subscriptions grew by 5.6 percent over the last one year to stand at 32.2 million at the end of the 2013/2014 financial year fourth quarter, translating into a mobile penetration level of 79.2 percent. The number of new subscriptions registered during the period was 416,390. Since then, there has been an upward trend on penetration of mobile phones in the country.

That kind of learning takes time, and with the rapidly changing technology industry, new tools are always being introduced. For teachers, it's a challenge especially for those in the developing countries to cope up with these new innovations and devices which at times don't make much sense to them.

One elderly adult respondent had this to say In relation to technology and space in education 
"There is too much over engagement with technology among learners hence the need to education policy to be changed to accommodate its use during class hour or students to leave them home and do their own

This study found that the use of ICT and other digital devices in education has brought changes in the teaching and learning process and it is no longer the teacher as the owner of knowledge but the learner is also capable of getting independent knowledge which he or she can use effectively. This is in line with various researches agree that the use of ICT in education in general, and the Web, has consequences for the organization of education and how the teacher and the student relate. And with the mobile devices, they agree that their important features like portability, mobility and versatility remain the same. So \& Kint( 2008) noted that, these functions make learning ubiquitous in and out of classrooms, provide potential opportunities for collaborative learning and enrich the learning experiences with the support of technologies.

This study, find out that, the students spend more time using computers than the tutors and even carried more electronic mobile devices like laptops to class unlike the instructors though $97 \%$ of the instructors the respondent noted carried their mobile phones to class. This is in line with the findings of other study findings like Heidi and George S (2014) on teacher preparation progarmes and technology integration that noted variations in use of technology by various categories of students who were involved in the study.

As the students use various technologies for learning and teachers for teaching purposes, there is also a perspective from outside of the classroom that this one magic app will solve all of the problems which may not be the case. Hence, technology is not the silver bullet and for some reasons, it doesn't replace the teaching and learning process.

\section{Conclusion}

In summary, we can say that, the feedback and final results of this study and others carried elsewhere by others in relation to electronic mobile devices, technology and learning, especially mobile learning and its related devices, there is an array of hope to use mobile devices for learning purposes as leaners use them in class and out of class for learning purpose though the measure of the impact of using them is yet to be effectively established. There's an exponential increase in use of apps and the respondents indicated that at times they are not able to cope with the new apps or it passes or becomes outdated before they even down load for use. $T$

The study also looked at affordability and how it relates to use of technology and there is a relationship between the income of the user and the gadget used. The more money one has, one is likely to but a good technological device for use. The other conclusion is that, despite the high penetration of smart phones in the continent, not all students have smart phones hence are limited to level of and interaction in the online learning space .

\section{References}

Aseey A. Anne (2009) the potential impact of integrating ICT into students support services in distance education. The case of the University of Nairobi, Published PhD Thesis

Bennet,S.(2008) The Digital Natives: A critical review of the Online British Journal of Educational Technology,39;5,pp 775-786

Republic of Kenya. Kenya gazette Supplement .Constitution of Kenya 2010.The Government Printer, Nairobi

Education 2030: Incheon Declaration and Framework for Action for the implementation of Sustainable Development Goal 4 Ensure inclusive and equitable quality education and promote lifelong learning opportunities for all. Incheon, Korea 2015

Gakuu, C.M. (2007).Analysis of the factors and attitudes that influence lecturer's readiness to adopt Distance Education and the Use of ICT in teaching: The University of Nairobi Case.

Heidi L. Schnackenberg \& George Still III (2014). Teacher Preparation Programs And Technology Integration: Best Practices For Curriculum Design. International Journal of Education and Practice, 2014, 2(7): 147158 Journal homepage: http://pakinsight.com/?ic=journal\&journal=61 
Mboroki.J.G. (2007).A comparative study of performance in teaching practice between the Bachelors (Arts) onCampus students and Distance study students: The case of the University of Nairobi (Unpublished PhD Thesis)

Mugenda Olive and Mugenda G. (1999). Research Methods Qualitative and Quantitative Appropriates. Nairobi, Africa Centre or Technology Studies (ACTS) pressDevelopment, University of Manitoba.

Siân Bayne and Jen Ross( 2007). "The 'digital native' and 'digital immigrant': A dangerous opposition," paper presented at the Annual Conference of the Society for Research into Higher Education (SRHE) [December], and at http://www.malts.ed.ac.uk/staff/sian/natives_final.pdf, accessed 21 October 2012.

Kenya Vision 2030(2007). A globally competitive and prosperous Kenya. Government of the Republic of Kenya, Ministry of Planning and National Development and the National Economic and Social Council (NESC), Office of the President

Roxana Bassi (2013).MIT-Haiti Initiative Uses Haitian Creole to Make Learning Truly Active, Constructive, and Interactive .Education technology debate .Exploring ICT and learning in Developing 2013 July 26, 2013 03:13 am |

Robert B. Kvavik, Judith B. Caruso, and Glenda Morgan, 2004. ECAR study of students and information technology 2004: Convenience, connection, and control. Boulder, Colo.: EDUCAUSE Center for Applied Research, athttp://www.educause.edu/ir/library/pdf/ers0405/rs/ers0405w.pdf, accessed 15 October 2012.

Terry Judd \& Gregor Kennedy (2010).A five -year study on -campus internet use by undergraduate biomedical students. Elsevier. Computers and education 55(2010)1564-1571.doi.10.10.1016/j.comedu.2010.06.022

UNESCO. (2001). Statistical Yearbook. Paris: United Nations Educational, Scientific and Cultural Organization. World Bank (1998). Priorities and strategies for education: a World Bank review. : World Bank

Siân Bayne And Jen Ross (2014). 'Digital Native' and 'Digital Immigrant' Discourses A Critique. The Quarterly Sector Statistics Report October, 2014 